\title{
The Potential Impact of Rate-Based or Mass- Based Rules on Coal-Producing States under the Clean Power Plan
}

Simulations clearly show that the choice of rate- or mass-based standards potentially creates significant differences in incentives regarding investments in natural gas and renewable generation, and therefore the preservation of coal generation. The modeling suggests these incentives could have significant effects on coal generation outcomes, and by implication coal production in the future.

\section{Robert Godby ${ }^{a}$, Roger Coupal ${ }^{b}$}

Robert Godby is Director of the Center for Energy Economics and Public Policy (CEEPP) and also an Associate Professor in the Department of Economics and Finance at the University of Wyoming. His main areas of research interest are energy economics, resource and environmental economics, and macroeconomic policy.

Roger Coupal is the current Department Chair for the Agricultural and Applied Economics Department at the University of Wyoming. His research areas include regional economics and natural resource policy.

\section{${ }^{a}$ Economics and Finance, ${ }^{b}$ Agricultural and Applied Economics University of Wyoming}

\section{Introduction}

Under the final Clean Power Plan (CPP) rules, among the first decisions states will have to make is whether to adopt $\mathrm{CO}_{2}$ rate- or mass-based standards when adopting an implementation plan to control greenhouse gas (GHG) emissions from existing natural-gas- or coal-fired power plants. Under a rate-based plan, states adopt emissions standards defined as a limit on $\mathrm{CO}_{2}$ emissions per unit of electricity produced at regulated generators within a state. Under a mass-based plan, $\mathrm{CO}_{2}$ limits are defined as a finite total mass of emissions allowed across covered facilities within a 
state and covered generators must hold allowances to emit, where the total allowances available to firms sum to the state cap. The Environmental Protection Agency (EPA) has allowed states to choose either rulemaking standard and has defined $\mathrm{CO}_{2}$ limits in each case in the final CPP rules for existing plants released on Aug. 3, 2015. ${ }^{1}$

The EPA has encouraged states to allow emissions trading to meet the limits of the CPP; however, states submitting to regulation under rate- or mass-based plans may only trade or cooperate with other states that choose to regulate under the same type of emissions standards. Historically, under Section 111(d) of the Clean Air Act, existing sources of emissions for other pollutants have been regulated using emissions rates. States regulating and trading emissions, however, have decades of experience regulating conventional pollutants under a mass-based standard, and previous $\mathrm{CO}_{2}$ trading programs like the Regional Greenhouse Gas Initiative also define standards using mass-based limits. ${ }^{2}$ The EPA claims that under their analysis, limits using rate or mass-based standards should lead to achieving an equivalent emissions goal. The choice of how to regulate, however, creates different incentives for states regarding compliance strategies, and EPA analysis indicates that mass-based standards may result in a lower total national cost of emission control. Other analyses differ, including one described here. Actual costs of pollution control will depend on how states choose to regulate, what standards states choose, and whether states themselves prefer regulating under standards they are more familiar with.

The incentives under each type of standard are quite different and the implications for regional economic impacts may also be quite different. A rate-based standard defines an intensity of emissions per megawatt-hour (MWh), and can dynamically adjust as changes in demand occur. For example, if demand increases, requiring greater generation, the actual emissions rate experienced will depend on how new generation is met. If the new load is met with lowemissions generation, the rate occurring could fall despite an increase in emissions. Under a ratebased standard, low-emissions generation may also allow other higher-emissions sources to continue operation through the creation of emission reduction credits. Under a mass-based standard, the emissions cap would be unaffected and this is not possible. This could have implications for coal production and the economic costs of the CPP regulation for coal producing states. This article investigates the potential implications of choosing rate-based or mass-based 
standards on coal producing states using a series of proprietary simulations based upon the National Energy Modeling System (NEMS) performed by the Rhodium Group. ${ }^{3}$

\section{Background}

Final Clean Power Plan rules for existing power plants were announced on Aug. 3, 2015. If upheld, these rules aim to reduce U.S. greenhouse gas emissions from the power sector by $32 \%$ from 2005 levels by $2030 .^{4}$ The final rule changed several areas of the 2014 proposal, though a review of all the changes is outside the scope of this article. ${ }^{5}$ The 2014 rules streamlined the ability of states to engage in regional cooperative strategies to reduce the costs of implementing the new regulations, and the final rules attempt to encourage such actions. The changes also made the rules more consistent with other stationary source regulations under the Clean Air Act (CAA). For example, the original 2014 proposal potentially allowed states to decide the compliance entity accountable for ensuring regulations are met. In the proposal the responsible entity could have ranged from individual sources, to utilities and their fleet of sources, to state agencies overseeing all sources within a state's borders. The 2015 rule makes the individual emitter solely responsible, which is consistent with other CAA regulations. This also simplifies the rulemaking for emissions trading and other market-based strategies for compliance by allowing trade to more easily be defined between sources. The final rule also includes model trading rules to help facilitate and coordinate the development and organization of such trading efforts.

Importantly, to ensure consistency with other CAA regulations, which have historically been defined in terms of emission rates, but also with the fact that existing trading efforts in GHGs define mass-standards, targets for states were defined under both rate- and mass-based standards. Among the first decisions states will have to decide is whether to adopt $\mathrm{CO}_{2}$ rate- or mass-based standards when formulating their state implementation plans (SIPs). ${ }^{6}$ In the final rule, these are due by Sept. 6, 2016, unless an extension is requested, in which case states may have until 2018 to develop their respective plans, including multistate cooperative plans such as emission trading across state lines. ${ }^{7}$ If states do not submit such a plan a Federal Implementation Plan (FIP) will be imposed within two years of non-compliance. Currently, a final FIP is not defined; however, two proposals currently exist - one a mass- and the other a rate-based plan. ${ }^{8}$ Importantly, states 
adopting mass- or rate-based standards will only be allowed to create such trading plans with other states adopting regulation under a similar standard.

Under both mass- or rate-based rules, the EPA originally estimated that the choice of regulation would not fundamentally change emissions outcomes; however, their simulations did indicate that this choice could alter the total incremental cost of the rule, and costs faced by consumers. Modeling the 2015 rules assuming a nationalwide trading regime and single mass- or rate-based choice by all states, the EPA estimated the incremental cost of the CPP above a business as usual (no-CPP baseline) of between $\$ 5.1$ billion under a mass-based approach to $\$ 8.4$ billion under the rate-based approach. Despite these added costs, the EPA (2015) estimated that the average consumer's electricity bill would decrease by between $7 \%$ and $7.7 \%$, respectively, by 2030 due to reduced power consumption and energy efficiency measures, while retail electricity rates were nearly unchanged from their business as usual projections. ${ }^{9}$

The emphasis on emissions trading in final 2015 CPP rules is consistent with several modeling results for rules under the 2014 proposal, which found that wider trading reduced significantly the potential cost of meeting the $\mathrm{CO}_{2}$ standards of the CPP. ${ }^{10}$ Reduced costs of implementation also reduce the impact of the rules on coal producing states like Wyoming as shown in Godby et al. (2015 a,b) and Godby and Coupal (2016). Those results, using simulation results from Larsen et al. (2014) and the EIA (2015) to estimate state impacts as well as state revenue outcomes for the implementation of the 2014 CPP rules showed that wider trading could reduce such impacts from by $7-8 \%$ in the case of employment losses for Wyoming, the nation's largest coalproducing state. ${ }^{11}$

Previous simulations on the originally proposed rules have also indicated the sensitivity of potential outcomes to assumed conditions in the natural gas and coal markets, and assumptions regarding renewable costs. Some of these are described in Godby and Coupal (2016). In particular, earlier simulations like those used in Larsen et al. (2014) and across the results reported in Hopkins (2015) used EIA's Annual Energy Outlook 2014 (AEO2014) modeling assumptions and generally identified displacement of coal with natural gas generation as the predominant means of meeting new $\mathrm{CO}_{2}$ regulations. Higher natural gas prices and lower coal production costs, along with lower renewable cost assumptions embodied in the EIA's AEO2015 assumptions, however, lead to a different outcome, and result in EIA (2015) finding renewables, 
particularly wind generation, the most important means by which the proposed $\mathrm{CO}_{2}$ limits would be met in the 2014 CPP proposal. In these projections, natural gas plays a less prominent role and displaces less coal-fired generation. This difference in conclusions highlights the sensitivity of potential CPP outcomes to changes in energy markets.

More recently, additional changes to the economic landscape have potentially altered possible outcomes of the CPP and how it may be implemented. In addition to the final rule changes in August 2015, the U.S. Congress made unanticipated and significant changes to renewable incentives in late December $2015 .{ }^{12}$ Specifically, this action restored previous incentives to develop new renewables and guaranteed such assistance until at least 2020. The wind production tax credit (PTC), which previously expired in 2014, was reinstated. It will now pay 2.3 cents per kilowatt-hour generated for the first 10 years of output for all new wind projects begun in 2015 and 2016. It will then drop to $80 \%$ of this value in $2017,60 \%$ in 2018 , and $40 \%$ in 2019 before ending in 2020. Similarly the investment tax credit for solar projects, which was set to drop to $10 \%$ of project costs in 2016 , will now decline from $30 \%$ to $12 \%$ by 2020 in $6 \%$ increments annually starting in 2017 , before finally dropping to $10 \%$ in 2021 . Overall, after years of inconsistent policy causing significant investment uncertainty for renewable energy sources, these new rules allow a much more favorable and predictable environment in which to develop such projects.

Given the more favorable conditions for renewable energy projects, this could further alter energy market outcomes and the impacts regulations like the CPP have on energy dependent economies, especially those that produce coal. Additionally, the new CPP rules introduced in 2015 potentially create incentives that could cause the impacts experienced by such economies to be altered by the states' choices regarding how they choose to be regulated. The following sections describe how the state choice between rate- and mass-based regulations could impact generation mixes and resultant demands for coal, and describes simulation outcomes that attempt to quantify these results.

\section{Incentives matter}

As described, among the first choices states must make under the CPP is whether to be regulated by mass- or rate-based standards. While estimated emissions impacts for states universally choosing one or the other type of standard have been estimated to be nearly identical by the EPA 
under the final CPP rules, how these choices affect the method of delivering these reductions may be markedly different. Added to that, newly reinstated tax credits potentially increase the competitiveness of renewable generation and may alter investment decisions to meet potential $\mathrm{CO}_{2}$ targets.

With respect to incentives, consider how a rate-based standard expressed in pounds of $\mathrm{CO}_{2}$ emitted per megawatt-hour (lbs. $\mathrm{CO}_{2} / \mathrm{MWh}$ ) could affect generation decisions under an emission trading system. Any existing fossil-fuel generator with an emission rate higher than the standard set by the EPA must either reduce their emissions to the rate required through plant modification, or acquire enough emission rate credits (ERCs) denominated in MWh to bring their emission rate into compliance. Such credits can be created under the 2015 CPP rules by any existing fossil-fuel generator with an emission rate below applicable standards, or by any new zero-emitting source such as renewable or nuclear generation built after 2012, and sold directly or through third parties to initially non-compliant sources. Revenues from such sales effectively reduce the net cost of operation of credit generating sources, making them more competitive in electricity markets, while increasing the costs (through permit purchases) and reducing the competitiveness of those sources that do not meet the EPA's performance standards, altering the generation mix. These incentives may also alter the investment decisions made with respect to new generation choices in the future to comply with regulations or to accommodate new load growth. Since only zero-emission generation built after 2012 is eligible to create ERCs there is an increased incentive under rate-based regulation to build new renewable (and new nuclear to a lesser degree) generation. New load growth allows dynamic adjustment of the power system to accommodate such growth while potentially allowing the regulatory impact on coal-fired generation to be reduced by the creation of credits.

Under a mass-based standard, each state has an allowable level of total emissions defined in tons of $\mathrm{CO}_{2}$ that it can emit from its generating sector. These are allocated by states to generators. All fossil-fueled generators must hold emission allowances to cover their operating emissions. If these allowances are allocated in an allowance auction, these sources all see their costs rise, and the higher the emissions of any given source, the greater the cost incurred to purchase allowances. Less emissions-intensive sources such as natural gas combined-cycle (NGCC) power plants face reduced cost increases relative to more emissions-intensive technologies such 
as traditional coal-fired plants, resulting in greater NGCC relative market competitiveness than without such regulations. Absent any other incentives this would result in greater use and deployment of NGCC technologies and less coal generation. Note that zero-emitting sources do not have to hold allowances, but they also do not create allowances for resale and therefore while NGCC and coal-fired generators see increased costs, non-emitting sources do not see the additional cost improvements available to such generators under the rate-based alternative. The result then is potentially less incentive for investments in new renewable capacity under a massbased scheme than under a rate-based one, while new NGCC plants may have increased investment incentives relative to other forms of generation.

For coal-fired generation, and by extension, suppliers of coal for such plants, these incentives have important implications. Coal under any $\mathrm{CO}_{2}$ control policy will be challenged due to the emissions intensity of that fuel; however, under a rate-based scheme new renewables can create the credits that may allow some coal plants to remain in operation, especially in the presence of greater load growth. Rate-based schemes may also alter the rate of load growth if they result in lower electricity prices than under a mass-based alternative. Under a mass-based scheme, load growth does not alter the emissions mass cap, thus a relative advantage will always exist between coal and natural gas generation due to the relative emissions intensity of the two fuels, creating a greater incentive to replace coal-fired with gas-fired generation. By implication then, a ratebased scheme could preserve greater coal generation and reduce the impact of carbon regulations on coal-mining states. New renewable incentives in the form of production and investment tax credits could further reinforce the incentives to build additional renewable generation and magnify the potential advantages of states choosing a rate-based regulation for coal-producers under the CPP.

\section{Simulation results}

To estimate the potential impact of both the new CPP rules changes and the tax credit changes recently passed by Congress, Rhodium Group performed a series of simulations using their implementation of the EIA's NEMS model (RHG-NEMS). ${ }^{13}$ Simulations assumed the AEO2015 assumptions, adding the newly passed 2015 tax credit extensions without the CPP as a reference scenario, and implemented either rate- or mass-based rules assuming all states chose either a rate- or mass-based regime imposing CPP standards as defined in the 2015 rule. In both CPP 
scenarios a nationwide trading market was assumed also. The mass-based scenario was implemented assuming all existing and new fossil-fueled generators are covered and allowance auction revenues were not returned to consumers or the power sector, or used to pursue any other policy goal. ${ }^{14}$ Results illustrate the effects of all states implementing rate- or mass-based programs in a model-consistent context. To be consistent with the 2015 CPP rules that use the year 2012 as a baseline, results are shown from that year and run through 2030, the year final CPP standards are required to be achieved. ${ }^{15}$

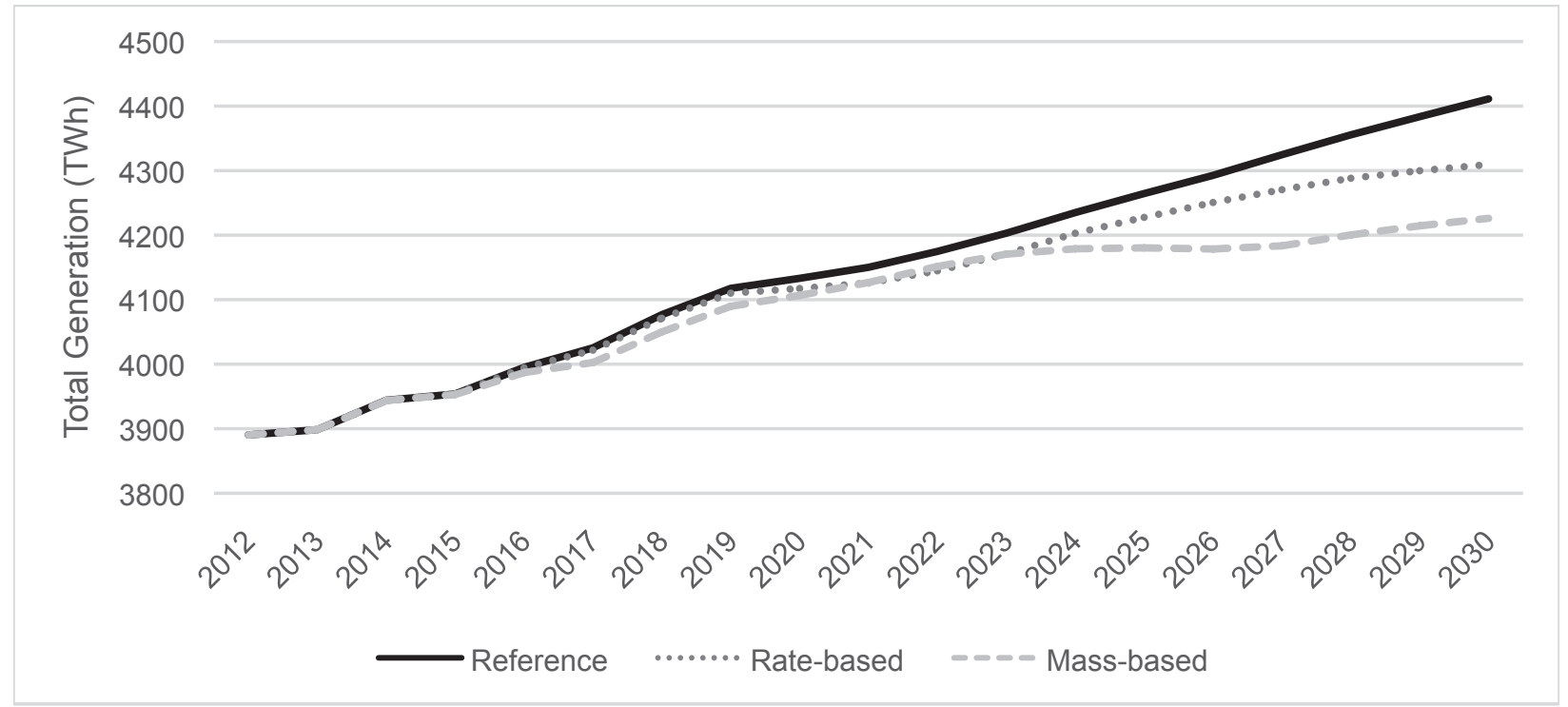

Figure 1: Total generation outcomes from 2012 to 2030.

Generation outcomes under the scenario are shown in Figure 1. Without the CPP imposed, but including the newly passed renewable tax credit extensions and assuming market conditions and assumptions consistent with the EIA's AEO2015, projected electricity sales by 2030 would increase by $13.4 \%$ relative to those in 2012. As reported in Larsen et al. (2016c), implementing the CPP results in electricity rates rising and reduced consumer sales due to additional investment and control costs necessary to meet the rules. This occurs regardless of a rate- or mass-based choice by states. The mass-based scenario assumes auctioned permits raise costs at all fossil-plants, while zero-emissions plants are unaffected, raising rates. In the rate-based system the cost of ERCs reduce zero-emission sources' costs while increasing fossil-fueled sources thus the rate impact is not as severe. ${ }^{16}$ The overall result is that in the mass-based case the reduction in electricity demand due to higher rates is more significant relative to the reference case, dampening predicted electricity growth to $8.6 \%$ between 2012 and 2030. In the 
rate-based case it grows by $10.8 \%$. As reported in Larsen et al. (2016c), overall expenditures for electricity in the mass-based case rise by $11 \%$ relative to the reference case by 2030 and only $1.1 \%$ in the rate-based scenario.

Capacity additions by scenario are shown in Figures 2, 3, and 4 for coal, NGCC, nuclear, and fossil with carbon capture, wind, solar, and all other generation. In the reference case without the CPP, coal retirements total $48 \mathrm{GW}$ by 2030 and occur by 2025. Wind increases by $67 \mathrm{GW}$ and solar by $12 \mathrm{GW}$ by 2030 relative to 2012 levels, while NGCC generation increases by $42 \mathrm{GW}$ over the same period. Both CPP scenarios result in greater retirement of coal-fired generation than under the reference case - in the mass-based case $81 \mathrm{GW}$ is retired by 2030 while in the rate-based case retirements total $73 \mathrm{GW}$. How this is replaced by new NGCC and renewable buildout differs in each case.

Under the mass-based scenario, NGCC additions total 42 GW by 2030 , virtually the same as that projected in the reference case. Wind and solar increase relative to reference with a total of 102 GW of wind and $29 \mathrm{GW}$ of solar added by 2030. Under rate-based regulation, however, NGCC additions at $16 \mathrm{GW}$ are over $60 \%$ less than the reference and mass-based cases, while wind additions are more than double the reference and over 40\% more than the mass-based case at 146 GW. Solar additions are over four times the reference outcome at $50 \mathrm{GW}$. Overall, new capacity additions in both CPP scenarios occur relative to the reference case to make up for lost coal generation, but because rate-based rules allow only generation built after 2012 to generate ERCs, there is a significantly greater incentive to build out new renewable generation. Conversely the incentive to exploit natural gas is reduced under rate-based relative to mass-based regulation. 


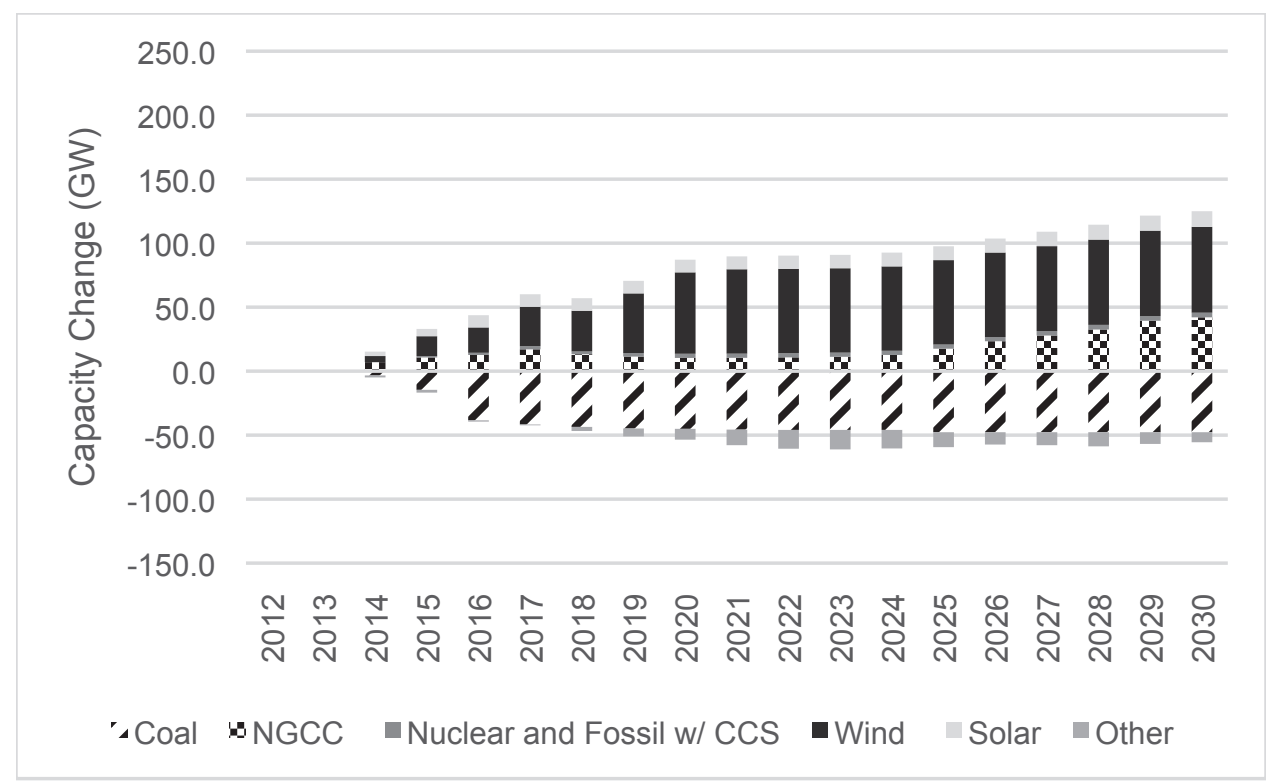

Figure 2: Reference scenario: Cumulative capacity changes by generation type relative to 2012

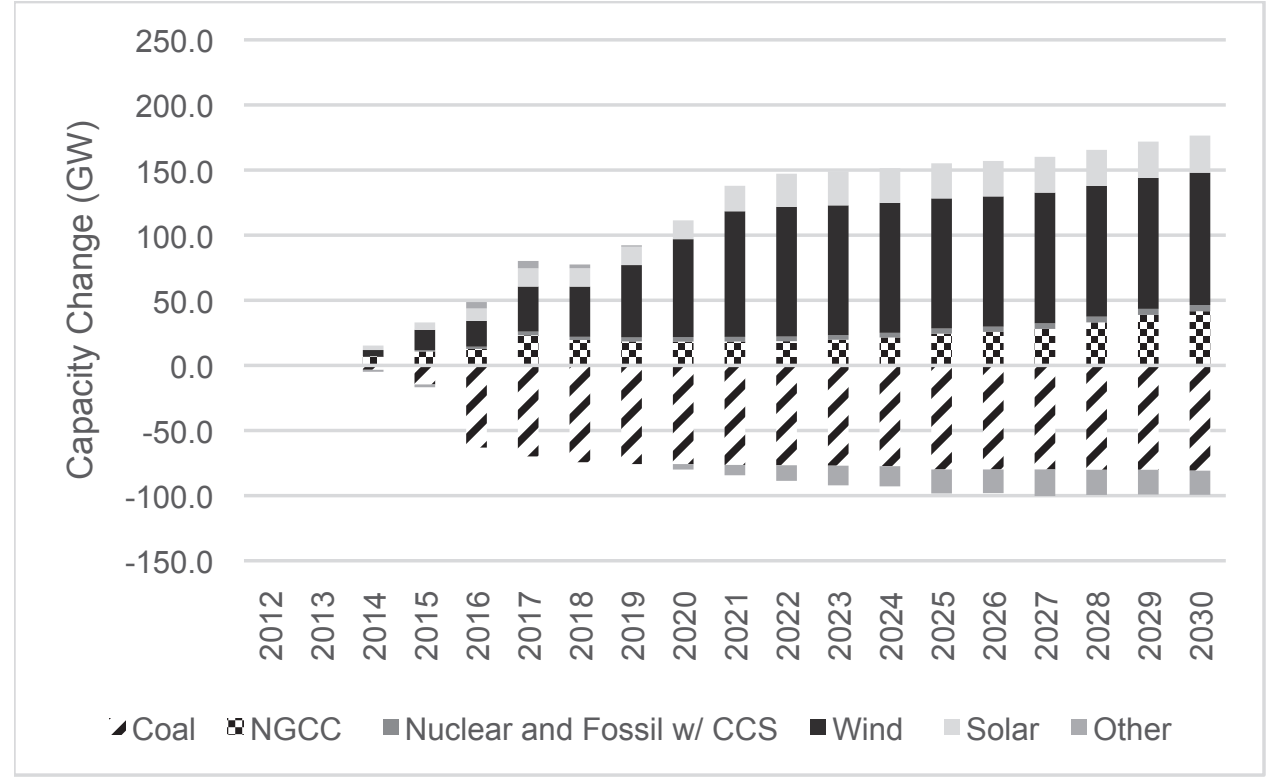

Figure 3: Mass-based scenario: Cumulative capacity changes by generation type relative to 2012 


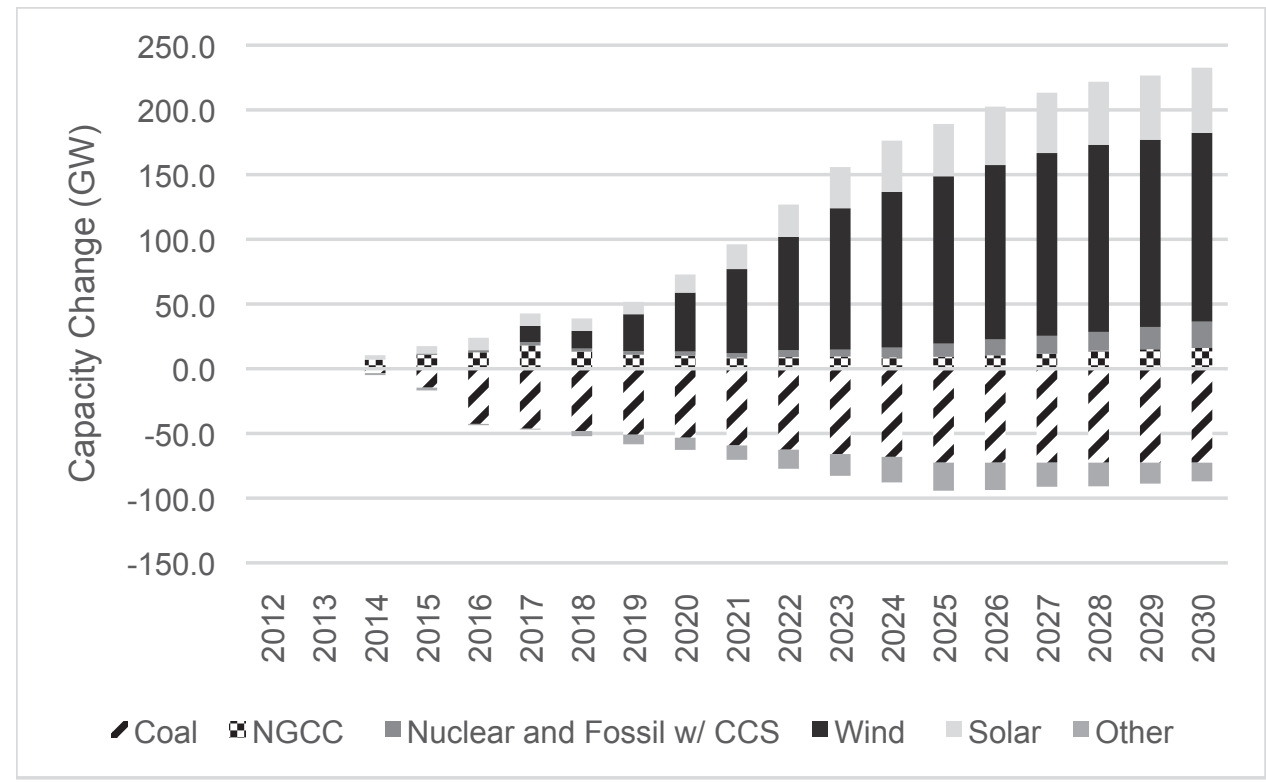

Figure 4: Rate-based scenario: Cumulative capacity changes by generation type relative to 2012 Generation outcomes also indicate how the choice of rate or mass-based regulation leads to different outcomes. Figures 5, 6, and 7 show the change in generation relative to 2012 for coal, NGCC, nuclear, and fossil with carbon capture, renewables, and all other sources of generation. ${ }^{17}$ In the reference case, renewable generation increases by $332 \mathrm{TWh}$ in 2030 relative to levels in 2012, while coal increases by $160 \mathrm{TWh}$ and NGCC by $79 \mathrm{TWh}$. Introduction of the CPP dramatically changes these results. In both cases total coal generation declines significantly; by 207 TWh by 2030 relative to 2012 levels in the rate-based case, compared to 302 TWh in the mass-based case. By 2030 the mass-based case results in a 20\% loss in coal-fired electricity production compared to 2012 , while the rate-based case declines by $13.7 \%$ over the same period. ${ }^{18}$ In the mass-based case, the relative improvement in NGCC competitiveness caused by the incentives this regulation choice creates causes NGCC generation in 2030 to rise by 204 TWh relative to the $973 \mathrm{TWh}$ produced in 2012. In the rate-based case, however, NGCC generation in 2030 declines by 166 TWh relative to 2012. Renewable generation outcomes are also dramatically different by scenario. In the mass-based case, renewable generation is 481 TWh higher in 2030 than 2012 levels, while the rate-based scenario results in a 730 TWh increase over the same period. ${ }^{19}$ Again, this reflects the difference in incentives for renewable use caused by the rate-based regulation. Together, under rate-based regulation, greater renewable generation, combined with higher load growth due to electricity rates, allows greater coal generation to survive given the introduction of the CPP. 


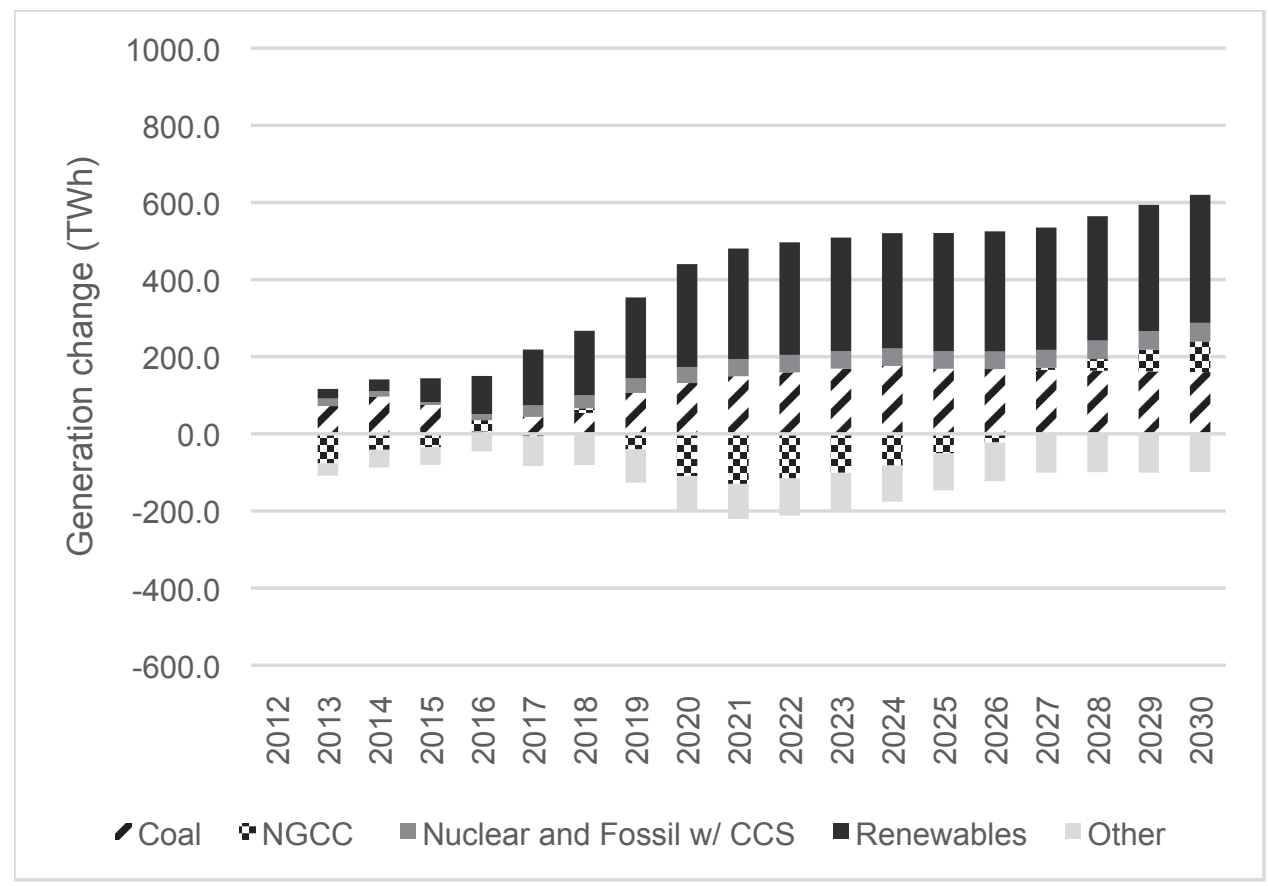

Figure 5: Reference scenario: Generation changes from 2012 by fuel type

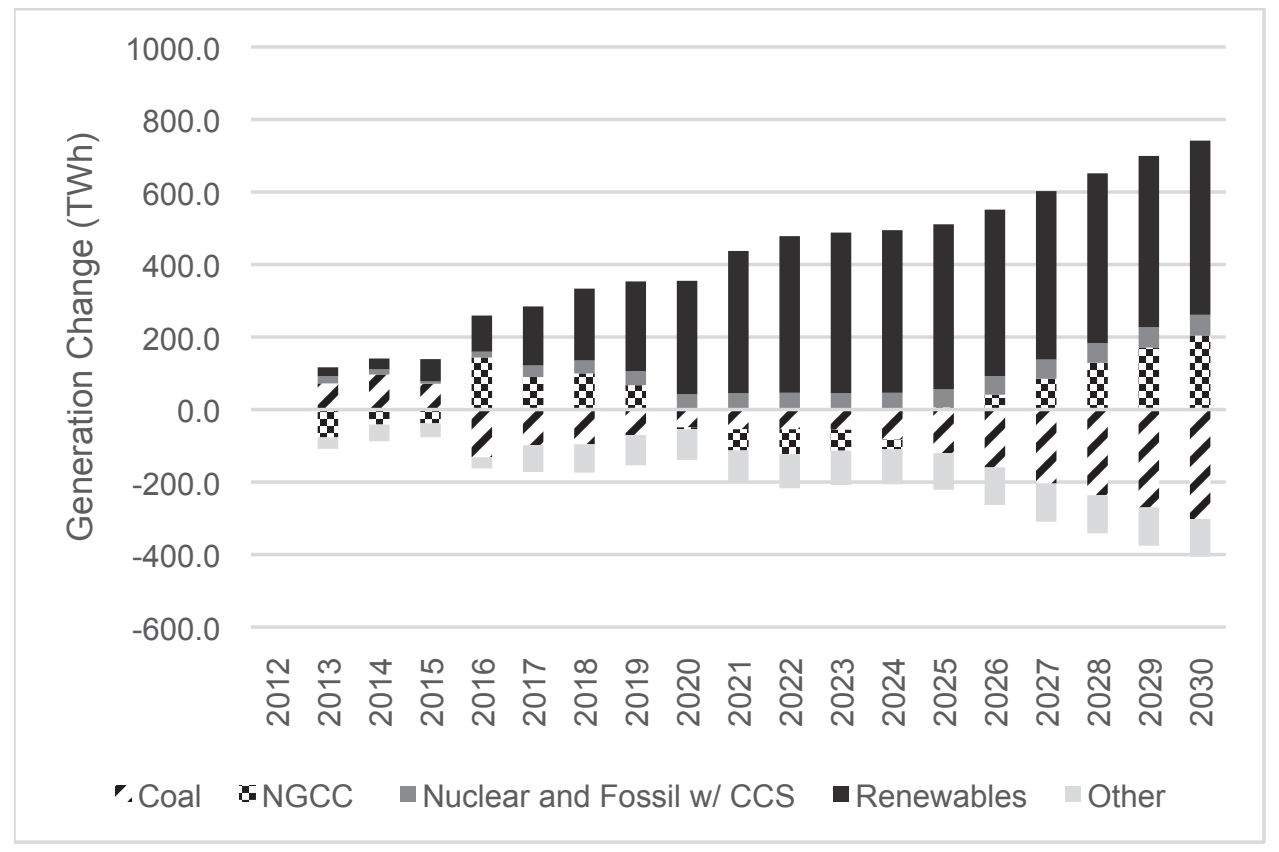

Figure 6: Mass-based scenario: Generation changes from 2012 by fuel type 


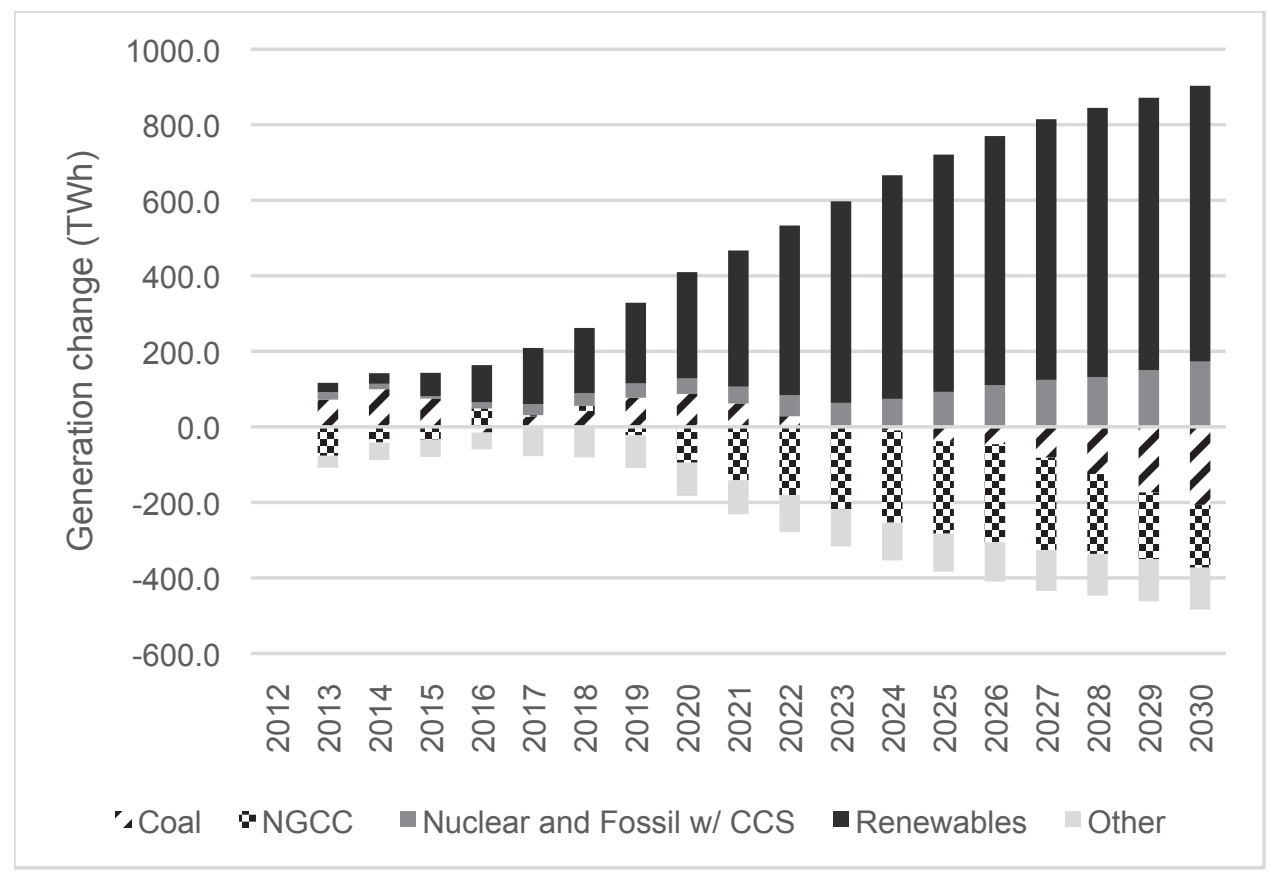

Figure 7: Rate-based scenario: Generation changes from 2012 by fuel type

Generation and capacity outcomes by scenario have significant implications for coal demand over time as well, as shown in Figure 8. Panels in Figure 8 describe the projected time-paths of coal production from 2012 through 2030 in the reference case and in the rate- and mass-based scenarios. ${ }^{20}$ As can be seen in the Figure, the no-CPP reference baseline would predict all regions shown except the Southwest and Appalachia to increase production. Appalachian production, however, declines due to increased coal competition from elsewhere in the United States, particularly the Wyoming Powder River Basin (PRB) and Midwest as relative costs increase over time to mine in Appalachia, and customers' coal-fired power plants are retired due to age in these regions. Reinvestment occurs with other forms of generation, as noted when describing projected capacity changes.

The remainder of the country in the reference forecast would be predicted to see a resurgence in coal through at least 2022, with Midwestern coal competitiveness increasing through the entire forecast period. ${ }^{21}$ Midwestern coal growth comes primarily at the expense of Wyoming Powder River Basin output, which peaks in the reference projection in the mid-2020s. Midwestern production improvements occur due to relative cost improvements caused by technologies such as longwall mining, while PRB costs increase as overburdens increase and PRB mining reserves are reduced in quality. Adding to this is an increase in coal transportation costs due to the 
AEO2015 assumption of rising oil prices over time. ${ }^{22}$ Both effects limit the size of the PRB market after 2025, along with changes in the coal market as retirements occur in PRB-fueled plants. Still, despite these changes in relative market size between Midwestern/Interior/Gulf producers and PRB producers, the Powder River Basin remains the largest coal producing region in the country throughout the forecast period, producing $40.5 \%$ of the nation's coal in 2030 , an increase over its $38.2 \%$ share in 2012. The Interior/Midwestern/Gulf share of output rises to $22.8 \%$ of national output in 2030, an increase over its $17.7 \%$ share in 2012.

Across the country, imposition of the Clean Power Plan causes several effects. First, regardless of scenario the CPP results in significant declines in projected coal production for all regions and nationally relative to the reference case. These declines though, reflect the sensitivity of generation and new capacity outcomes to the rate- or mass-based case assumed to occur. In the mass-based case, U.S. total coal production declines by $21.4 \%$ from the level produced in 2012. In a rate-based setting, however, this is reduced to a $13 \%$ decline by 2030 . Under a rate-based setting, national coal production remains higher than the mass-based case throughout the projection period, peaking in 2020, while in the mass-based case the decline occurs immediately upon the imposition of the CPP in 2016, with some recovery in coal production nationally through 2023, and declines occurring afterward. Overall, by 2030 under the rate-based case national coal production is $10.6 \%$ greater than the mass-based case.

Impacts of the CPP are relatively unequal across the regions shown in Figure 8. In Appalachia, projected declines in coal production accelerate due to the CPP. In the Interior/Midwest and Gulf, projected increases in coal production are mostly halted by 2020, and production remains relatively constant thereafter. In the Southwest, coal production declines begin with the program introduction when without the regulation they were projected to remain relatively constant. In the Great Plains region, which is dominated by Wyoming PRB production, the outcome is somewhat similar to the outcome in the Interior/Midwest/Gulf as a projected increase in coal output through the next decade in the reference case becomes a decline. Generally, however, impacts on regional and national coal production are worsened under a mass-based standard relative to ratebased outcomes in all regions but the Southwest by the time the CPP is fully implemented in 2030. Southwestern outcomes are dependent on local market outcomes and production after 
2025 between rate- and mass-based outcomes differs by only between to 2 to 3 million tons of production per year.

With respect to production differences between rate and mass-based outcomes, the primary areas benefiting from the choice of rate-based regulation are the Wyoming Powder River Basin (and by extension the northern Great Plains states) and the Interior/Midwest/Gulf producers. In the former case, the choice of rate-based regulation allows coal production levels to avoid declines until after 2025. In the Interior/Midwest/Gulf case, increases in production in the period between 2016 and 2020 are larger and these production levels are then largely preserved through the rest of the projection period. Scenario-specific trends and outcomes are not as distinct in the other regions in terms of production volumes, and in Appalachia there is little difference between the rate- or mass-based outcomes until the late 2020 s.

Coal production outcomes in Figure 8 show how different generation and investment incentives affect coal production. Under mass-based regulation, NGCC generation investment is incentivized and given retirement decisions present in the period from 2016 through 2025, this leads to greater coal retirement. More dispatch substitution from coal to gas and a much larger buildout of the NGCC fleet also occurs. Under the rate-based alternative, higher demand for electricity coupled with the subsidy effect of a trading system that allows renewables to exploit the creation of ERCs to lower their costs, causes more renewables to be built instead of NGCC plants in anticipation of the CPP requirements. This creates less coal displacement in dispatch, fewer coal retirements, and creates credits that allow many coal-fired generators to remain in production longer or more intensely in the period from 2016 to 2025 than under the mass-based standard. These effects lead to higher coal demand in all regions under the rate-based case. Over time, however, as the stringency of the CPP standards increase, the presence of wind ERCs is not enough to forestall coal retirements and they accelerate in the period from 2025 to 2030. This impacts Appalachian and Southwestern coal-producers most. Overall though, across all regions the projection outcome is the same, more coal production is preserved under rate-based regulation over the period from 2016 to 2030. Less NGCC generation is built, coal generation is able to benefit from the creation of ERCs greater renewable investment allows, and thus greater amounts of coal generation stay in operation longer, creating greater coal production. 
The impact of the rate- vs. mass-based choice has important economic consequences on coalproducing states. For example, using the economic impact model described in Godby and Coupal (2016), Wyoming employment in the coal sector under the mass-based alternative is estimated to be almost 6,600 positions lower than under the reference case. Rate-based rules reduce this loss to 4,300 fewer jobs. Relative to 2012 employment levels in the Wyoming coal economy, overall losses under the mass-based rules represent $1.7 \%$ of state jobs, and in the rate-based case $1.1 \%$. These losses, while substantial, are much lower than those shown in Godby and Coupal (2016) where losses were in the $2-2.5 \%$ range by 2030 .

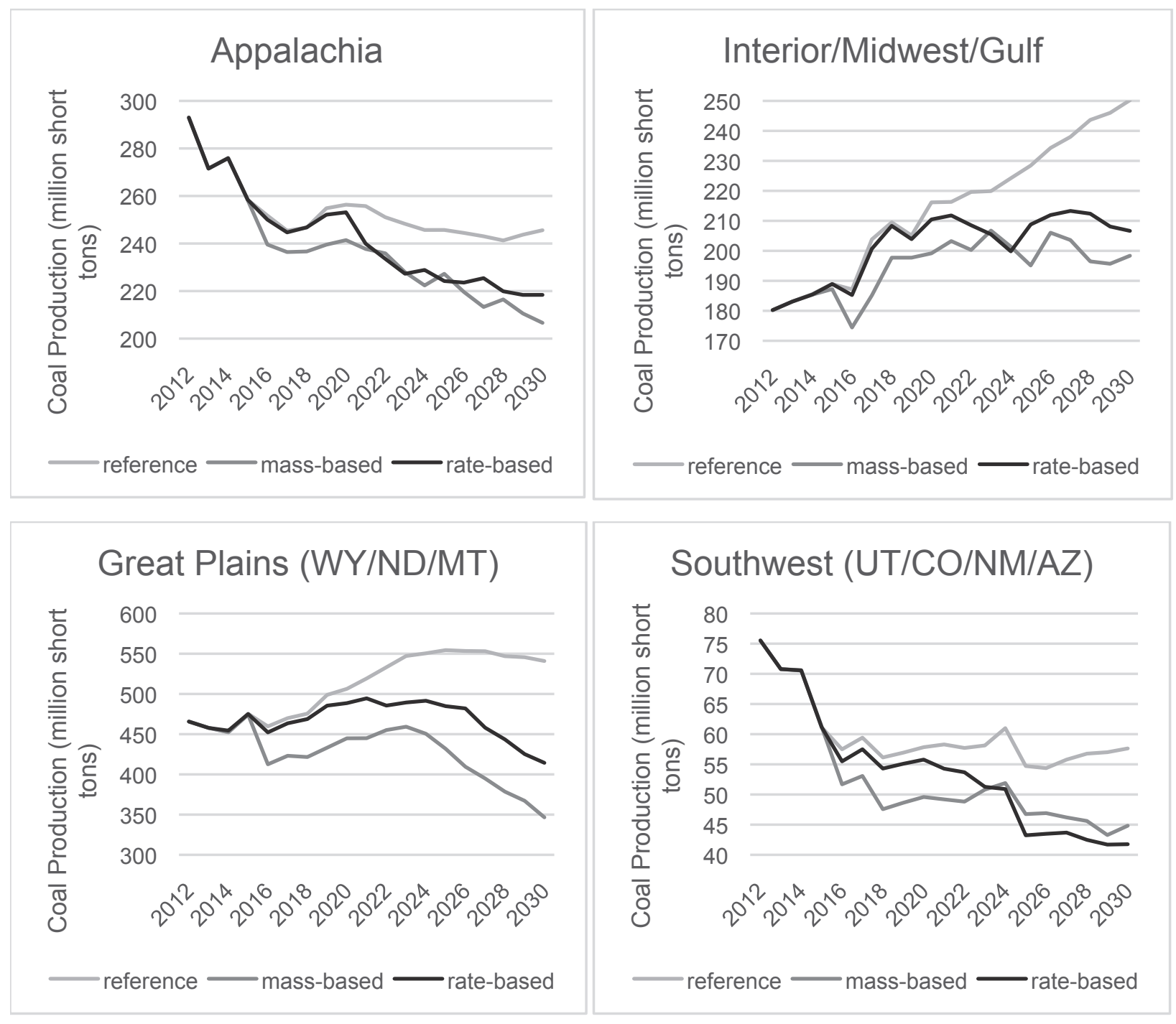




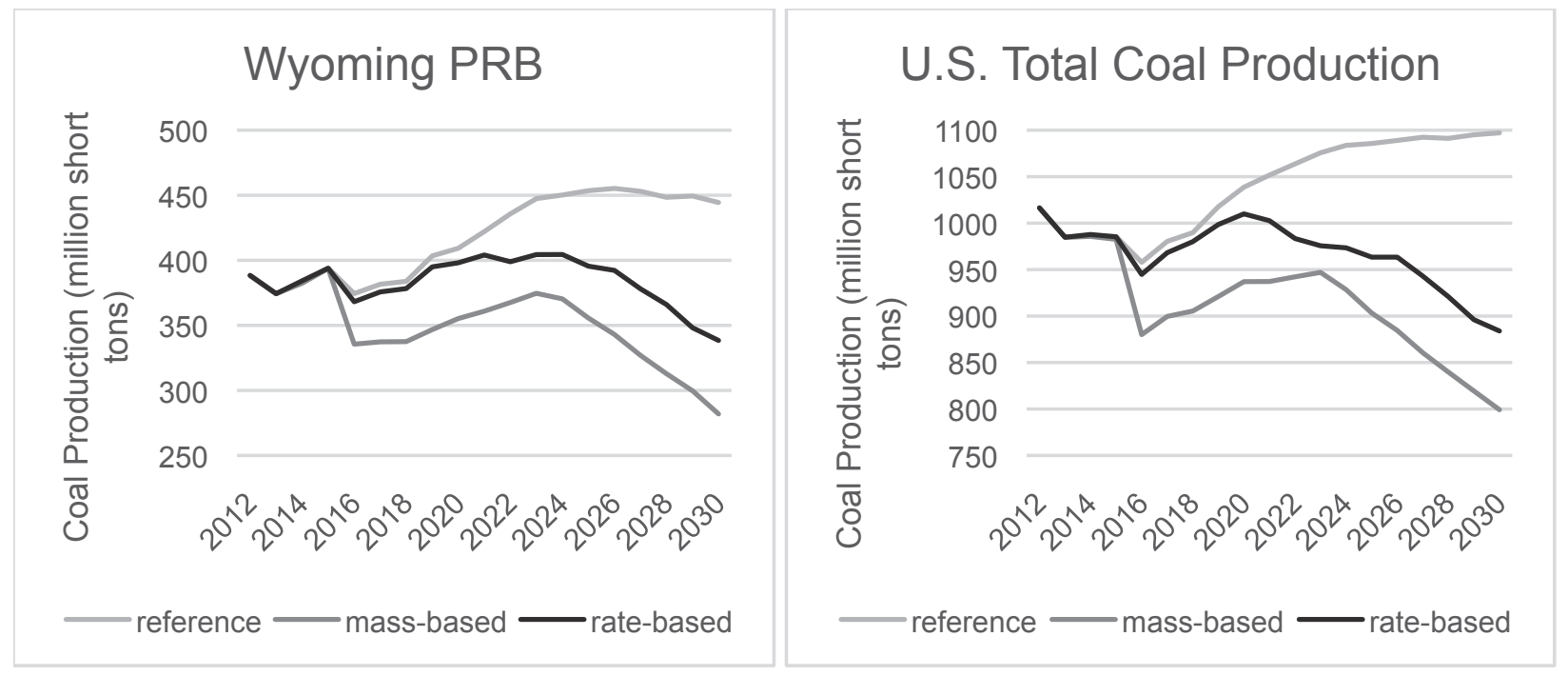

Figure 8: Coal production by region and simulation scenario (2012 to 2030)

\section{Conclusions}

Changes to the Clean Power Plan in August 2016 allow states to define their implementation plans under mass- or rate-based standards. Based on simulations by the EPA and by Rhodium Group, whose National Energy Modeling System simulation results are used here, the choice of standard should not dramatically affect emissions outcomes. The choices could, however, affect system costs and electricity rates. The EPA has also championed the use of allowance trading and regional cooperation to reduce the costs of compliance to these rules. The definition of rateand mass-based rules in such trading schemes creates potential incentives that, combined with the recent extension of renewable energy investment incentives, could greatly affect capacity investment decisions, generation outcomes, and therefore coal production outcomes. Specifically, under mass-based standards there may be an incentive for a larger natural gas combined-cycle buildout in generation capacity that reduces future coal generation substantially. While renewables are also encouraged by these regulations, they cannot offset the NGCC buildout nor can they offer help for coal-fired plants in meeting EPA regulations. The result is greater coal production declines.

Under a rate-based plan, however, renewable generation is encouraged because renewable sources can sell emissions reduction credits to $\mathrm{CO}_{2}$ emitters such as coal-fired power plants. Revenues from these sales create a subsidy and incentive to build out significantly more 
renewable generation, especially wind plants, which displaces investment in new NGCC plants. Less coal-fired generation is potentially displaced and the combination of greater renewable generation and greater coal-fired generation allows the system to meet required emissions outcomes. This preserves greater demand for coal-production. Renewables, in particular wind, and coal, become in effect strange bedfellows. Both enable the other in a rate-based regime.

Regardless of rate- or mass-based implementation, any GHG standards will be detrimental to coal production. These results suggest that coal producing states, while very likely not enthusiastic about the CPP, should have a clear preference regarding which type standard to prefer. Rate-based outcomes appear to have a greater chance of reducing this impact and greater preservation of coal production than mass-based standards. Many coal producing states such as Wyoming should also realize that it will not be their own choice regarding rate- or mass-based standards that matters, but what customer states choose to do. Given the simulation results presented, it would seem that coal-producing states therefore should emphasize coordination among as many states as possible, especially those using their coal to ensure that rate-based standards are adopted.

There are some caveats to this analysis. First, outcomes shown are best-case scenarios that occur under ideal conditions. For example, all states choose rate- or mass-based regulation and national trading occurs in both cases. This maximizes trading and cooperative opportunities. In all likelihood, a patchwork or regional groupings of states will emerge that make similar regulatory choices. How such patterns occur with respect to choice of standard could determine the trading opportunities available and this could affect generation and capacity choices in ways not foreseen. These could alter the results reported, and could worsen the impacts on coal production while increasing costs of compliance. Given this risk, it should be in the national interest to try to coordinate rate- or mass-based choices to minimize such inefficiencies. ${ }^{23}$

Second, changes in modeling assumptions made here could undermine the advantages of ratebased regulation for coal producers. AEO2015 assumptions and estimates of natural gas prices have proven much higher than actual outcomes in 2015 and 2016. Much lower gas prices than foreseen in this analysis could lead to the natural gas generation being more cost-competitive than assumed here, which could reduce renewable investment and undermine rate-based results that favor greater coal use. 
Thirdly, in the modeling presented here it is assumed allowance auction revenues in the massbased case are not used to achieve specific energy outcomes such as subsidizing renewable generation, or as consumer rebates that could reduce electricity rates and increase generation demand. In the mass-based case, using allowance auction revenues in this way could reduce the impacts on coal production for that regulatory choice. The assumption that allowances are not used in that way could exaggerate the differences between mass- and rate-based outcomes.

Finally, retirement decisions made in the simulations may not reflect considerations made in reality. For example, because NEMS assumes perfect foresight, modeled MATS retrofit decisions are made foreseeing CPP rules that will occur in the future. In the mass-based simulations, the combination of MATS retrofits and then anticipated high future CPP operating costs could cause firms to be projected to retire more coal-fired generation than may actually occur. In reality, MATS compliance choices have had to be made without knowledge of future CPP rules. This could cause the modeled mass-based decisions to be biased towards less coal use than has actually occurred in reality. ${ }^{24}$ Conversely, though, in the actual world the uncertainty regarding GHG rules at the time MATS decisions were made could have increased retirement over the model predictions, thus results under mass-based regulation presented could understate those that will eventually happen. The impacts of uncertainty regarding future GHG regulations have had in reality are difficult to know and quantify. This could also be true in the rate-based cases - conditions in reality may lead to larger coal-retirements than the simulation scenarios predict.

Overall, however, regardless of the limitations of using simulations, the results clearly show that the choice of rate- or mass-based standards potentially creates significant differences in incentives regarding investments in natural gas and renewable generation, and therefore the preservation of coal generation. Simulation modeling suggests these incentives could have significant effects on coal generation outcomes, and by implication coal production in the future. States attempting to minimize the cost of the CPP, and in particular, those states that are major coal-producers might consider that how their customer states choose to implement CPP rules could have major impacts on their coal production. For this reason, it may be in their interests to attempt to ensure such decisions are as coordinated as possible and that rate-based regulation is given maximum consideration. 


\section{Acknowledgements}

The authors thank the School of Energy Resources and Center for Energy Economics and Public Policy at the University of Wyoming for their financial support of this work, and Rhodium Group and John Larsen for their cooperation and data. The authors were also supported by the U.S. Department of Energy, Office of Science, Basic Energy Sciences, under Award No. DESC0012671.

\section{References}

Durkay, J. (2016) “States' Reactions to EPA Greenhouse Gas Emissions Standards," National Conference of State Legislatures http://www.ncsl.org/research/energy/states-reactions-toproposed-epa-greenhouse-gas-emissions-standards635333237.aspx. (accessed May 12, 2016).

Energy Information Administration (2015a), Analysis of the Impacts of the Clean Power Plan, May 2015, http:/www.eia.gov/analysis/requests/powerplants/cleanplan/pdf/powerplant.pdf (accessed May 12, 2016).

Environmental Protection Agency (2015) "Regulatory Impact Analysis for the Clean Power Plan Final Rule," October 23, 2015 www.epa.gov/sites/production/files/2015-08/documents/cppfinal-rule-ria.pdf (accessed May 12, 2016).

Godby, R., Coupal, R, Taylor, D.T. and Considine, T. (2015a) The Impact of the Coal Economy on Wyoming, Report prepared for the Wyoming Infrastructure Authority, Center for Energy Economics and Public Policy, University of Wyoming, February 2015.

http://www.uwyo.edu/cee/ files/docs/wia_coal full-report.pdf

Godby, R., Coupal, R, Taylor, D.T. and Considine, T. (2015b) "Potential Impacts on Wyoming Coal Production of EPA GHG Proposals," with Roger Coupal, David Taylor and Tim Considine, Electricity Journal, Vol. 28:5, pp. 68-79.

Godby, R. and Coupal, R. (2016) “A Comparison of Clean Power Plan Forecasts for Wyoming: the Importance of Implementation and Modeling Assumptions,” Electricity Journal, Vol. 29:1, pp. 53-62.

Hopkins, John (2015) Modeling EPA’s Clean Power Plan: Insights for Cost-Effective Implementation, Center for Climate and Energy Solutions, May 2015, http:/www.c2es.org/publications/modeling-epas-clean-power-plan-insights-cost-effectiveimplementation (accessed May 12, 2016).

Larsen, J., Ladislaw, S., Ketchum, W., Melton, M., Mohan, S., and Houser, T., Remaking American Power, Rhodium Group and Center for Strategic and International Studies, released November 2014. See http://csis.org/publication/remaking-american-power (accessed May 12, 2016).

Larsen, J., Ladislaw, S., Melton, M., and Ketchum, W. (2015) “Assessing the Final Clean Power Plan: Key Changes Relative to the Draft Rule and their Implications for Stringency," Rhodium 
Group and Center for Strategic and International Studies, released October 2015. See http://rhg.com/wpcontent/uploads/2015/10/RHG_ENR_CSIS_Assessing the_Final_CPP_2Oct2015.pdf (accessed May 12, 2016).

Larsen, J., Ladislaw, S., Melton, M., and Ketchum, W. (2016a) "Assessing the Final Clean Power Plan: Emissions Outcomes," Rhodium Group and Center for Strategic and International Studies, released January 7, 2016. http://rhg.com/reports/assessing-the-final-clean-power-planemissions-outcomes (accessed May 12, 2016).

Larsen, J., Herndon, W., and Larsen, K. (2016b) "What Happens to Renewable Energy without the Clean Power Plan?" Rhodium Group released Feb. 25, 2016 http://rhg.com/notes/renewableenergy-without-the-clean-power-plan (accessed May 12, 2016).

Larsen, J., Ladislaw, S., Melton, M., and Ketchum, W. (2016c) "Assessing the Final Clean Power Plan: Energy Market Impacts," Rhodium Group and Center for Strategic and International Studies, released May 2016. http://rhg.com/wpcontent/uploads/2016/05/AssessingCleanPowerPlan_EMI.pdf (accessed May 12, 2016).

Ramseur, J., and McCarthy, J. (2015) "EPA’s Clean Power Plan: Highlights of the Final Rule," Congressional Research Service, Aug. 14, 2015, https://www.fas.org/sgp/crs/misc/R44145.pdf (accessed May 12, 2016).

Endnotes:

${ }^{1}$ See the Clean Power Plan website maintained by the EPA at https://www.epa.gov/cleanpowerplan/clean-powerplan-existing-power-plants.

${ }^{2}$ The Regional Greenhouse Gas Initiative was the first mandatory market-based greenhouse gas emissions control program in the United States, and includes Connecticut, Delaware, Maine, Maryland, Massachusetts, New Hampshire, New York, Rhode Island, and Vermont. The program website can be found at www.rggi.org.

${ }^{3}$ Additional results from the simulations reported here can be found in Larsen et al. (2016a, b, and c), and Larsen and Herndon (2016).

${ }^{4}$ These rules are currently under a stay by the U.S. Supreme Court pending the resolution of legal challenges to the rule. The stay was granted Feb. 9, 2016, and the notice of stay can be found at

http://www.supremecourt.gov/orders/courtorders/020916zr3 hf5m.pdf.

${ }^{5}$ For a review of changes written shortly after the final rule was announced, see Ramseur and McCarthy (2015). Also, see Larsen et al. (2015) for a summary discussion.

${ }^{6}$ Under the mass-based standards, states will also have to decide whether to cover (i) only existing fossil-fuel generators while adopting a specific allowance distribution approach defined by the EPA in its model rules, or (ii) to cover both existing and new generation under a slightly higher cap defined by the EPA. This additional decision was necessitated by the fact that the rules for existing generators fall under the Clean Air Act's 111(d) portion of the rule, while new generators fall under separate 111(b) rules in the Clean Power Plan, which define emissions rates for 
new sources. Capping the emissions mass from existing power plants only could result in an incentive to build new fossil-fuel generators to avoid the rule's emission mass constraint, shifting generation to these new plants and thereby increasing total emissions beyond what the 111(d) rule intends. This is termed as "leakage" by the EPA. To avoid this incentive these additional considerations have been imposed on states opting for a mass-based plan to ensure that outcomes are broadly consistent with incentives and outcomes under a rate-based approach. For a deeper discussion and analysis of the potential impacts of leakage on CPP outcomes under a mass-based approach, see Larsen et al. (2016a).

${ }^{7}$ The U.S. Court of Appeals, D.C. Circuit will hear the appeal on Sept. 27, 2016. Since this is after the official deadline for states to submit initial implementation plans, the timetable of the rule will have to be delayed regardless of the appeal's outcome.

${ }^{8}$ A summary of the rule and its implications for state action can be found in Durkay (2016).

${ }^{9}$ Mass-based outcomes were modeled presuming only existing sources were covered, and that $5 \%$ of emissions allowances were set-aside to recognize and support the deployment of new renewable capacity. This is consistent with choice (i) in note 6 .

${ }^{10}$ Larsen et al. (2014) consider the impact or regional versus national trading on 2014 CPP proposal outcomes using their version of the National Energy Modeling System (NEMS-RHG), while Hopkins (2015) describes the results of several simulations across a variety of models. EIA (2015) also estimated costs of the 2014 proposed rules, including under three trading scenarios.

${ }^{11}$ Godby et al. (2015a, b) describes results for Wyoming for output, employment, and income as well as revenue outcomes. Godby and Coupal (2016) compares results for coal production and revenue outcomes using both Larsen et al. (2014) and EIA (2015) projections.

${ }^{12}$ See H.R.2029 - Consolidated Appropriations Act, 2016 https://www.congress.gov/bill/114th-congress/housebill/2029/text\#toc-H99A78113D3B9438997E3FAAB274EAA22 (accessed May 2, 2016).

${ }^{13}$ Larsen et al. (2016c) describes the specific simulation parameters assumed in the Appendix, while broad results of the simulations are reported in more detail in Larsen et al. (2016a, b and c).

${ }^{14}$ Revenues were presumed to be kept by government and not recycled in any way. Assume these revenues were added to state operating budgets. See Larsen et al. (2016c).

${ }^{15}$ As in AEO2015, model results are calibrated to actual outcomes through 2013, with results after that year reflecting simulation results.

${ }^{16}$ In the mass-based case, allowance costs raise all fossil-fuel generator costs, while trade in the rate-based case transfers costs among emitters. Both types of regulation would result in other costs to meet the regulation.

${ }^{17}$ Renewables in this case include wind, solar and geothermal/hydrothermal. Geothermal/hydrothermal were included as "Other" in Figures 2, 3, and 4. Overall impact of "Other" sources is very small in both sets of figures.

${ }^{18}$ In 2012, 1,511 TWh of electricity were produced from coal.

${ }^{19}$ In 2012, 468 TWh of electricity were produced from renewables.

${ }^{20}$ In Figure 8, Appalachian outcomes represent the sum of production in Pennsylvania, West Virginia, Kentucky, Ohio, Maryland, Virginia, Tennessee, and Alabama, and include metallurgical coal production.

Midwest/Interior/Gulf production includes Illinois, Indiana, Mississippi, Western Kentucky, Iowa, Missouri, Kansas, Oklahoma, Arkansas, Texas, and Louisiana outcomes. Wyoming PRB includes only production located in Wyoming, while Great Plains production includes Wyoming PRB and non-PRB, Montana, and North Dakota 
production. Alaskan and Washington coal production, which sum to less than 3 million tons per year between 2012 and 2030 , is not shown.

${ }^{21}$ Midwestern growth is primarily due to increases in production in the region including Illinois and Indiana.

${ }^{22}$ AEO2015 assumptions with respect to PRB production costs and oil prices are discussed in Godby and Coupal (2016). Midwestern production increases also occur as Mercury and Air Toxics Standards go into effect in 2016, causing a reduction in low-sulfur coal demand from the PRB due to induced plant retirements and reinvestments.

${ }^{23}$ It could be the case that some coal-producing states, to maximize the ability of their utility sectors to exploit regional cooperation, might find it to their advantage to adopt mass-based rules if nearby states who share the same electricity markets adopt them. Simultaneously however, these same states may prefer their coal customer states adopt a rate-based standard to minimize the impact on their coal production sector. This could put such a coalproducing state in the awkward position of conflicting interests - a "do as I say, not as I do" situation regarding coal-customer states' choices on rate- or mass-based regulation.

${ }^{24}$ We thank John Larsen at Rhodium Group for this observation. 